\title{
Lhermitte-Duclos Disease is a Component of Cowden Syndrome: Typical MRI Findings
}

Baadi $\mathrm{F}^{*}$, Zitouni $\mathrm{K}^{2}$, Gakosso $\mathrm{C}^{3}$, Boutakioute $\mathrm{B}^{4}$, Ouali Idrissi $\mathrm{M}^{5}$, Cherif Idrissi Ganouni $\mathrm{N}^{6}$

${ }^{1-3}$ Student in Radiology, Radiology Department, Arrazi Hospital, Mohammed VIth Teaching Center, Medical school of Marrakesh, Cadi Ayad University, Marrakesh, Morocco

${ }^{4-6}$ Professor in Radiology, Radiology department, Arrazi Hospital, Mohammed VI the Teaching Center, Medical school of Marrakesh, Cadi Ayad University, Marrakesh, Morocco

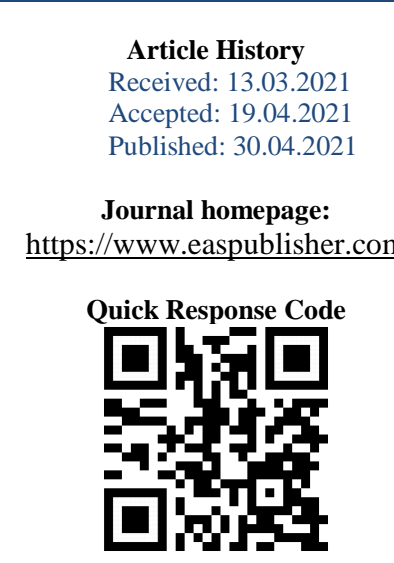

\begin{abstract}
Lhermitte-Duclos disease or dysplastic cerebellar gangliocytoma is a rare entity characterized by a hamartomatous lesion in the posterior fossa. Cowden's syndrome or hamartoma-neoplasia syndrome is a rare underdiagnosed autosomal dominant genodermatosis with high incidence of malignant tumors. Lhermitte-Duclos disease may be a component of Cowden's syndrome.

Keywords: Lhermitte-Duclos disease, dysplastic cerebellar gangliocytoma, Cowden disease, hamartoma, MRI.
\end{abstract}

Copyright (C) 2021 The Author(s): This is an open-access article distributed under the terms of the Creative Commons Attribution 4.0 International License (CC BY-NC 4.0) which permits unrestricted use, distribution, and reproduction in any medium for non-commercial use provided the original author and source are credited.

\section{INTRODUCTION}

Lhermitte and Duclos syndrome or dysplastic cerebellar gangliocytoma is a rare hamartomatous disorder, it is reported the first case of cerebellar ganglion cell tumor in 1920[1].

They performed a histologic examination of the lesion, found abnormally widened cerebellar folia with abnormal ganglion cells, and labeled it diffuse ganglioneuroma. Since then, many cases of LhermitteDuclos disease have been reported [2], and this disease is now called dysplastic gangliocytoma.

Some other names for this disease are granular cell hypertrophy, granulomolecular hypertrophy of the cerebellum, diffuse hypertrophy of the cerebellar cortex, cerebellar hamartoma, ganglioneuroma, gangliomatosis of the cerebellum, neurocystic blastoma, and hamartomoblastoma [3].

Cowden syndrome is the prototypic PTEN hamartoma tumor syndromes (PHTS), rare clinical syndromes characterized by germline mutations of the tumor suppressor PTEN [4].
The objective of this study is to determine the contribution of imaging in the diagnosis and management of this rare entity, in order to avoid complications.

\section{CASE Report}

A 44-year-old male patient presented the progressive cerebellar syndromes. This patient had a medical history: mesenteric desmoid tumor operated associated with digestive polyposis and thyroid goiter in the context of Cowden syndrome.

MR examination of the brain objectified a lesion of the left cerebellar hemisphere, of poorly defined contours, measuring 38x19.4 mm, with discreet T1 hypo intense (figure1), hyper intense T2 (figure 2) and FLAIR (figure 3 ) and unrestricted diffusion (figure 4), not enhanced after injection (figure 5); at Spectroscopy: increased Cho and NAA (figure 6).

This lesion had some prominent hypo- and isointense striations on the sequence T2 achieving a striated and lamellar appearance. 


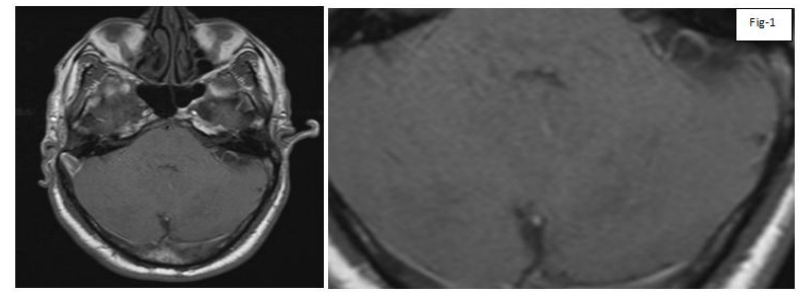

Fig-1: Axial T1-weighted shows lesion of the left cerebellar hemisphere, of poorly defined contours with the typical striated appearance, with hypo- and isointense bands

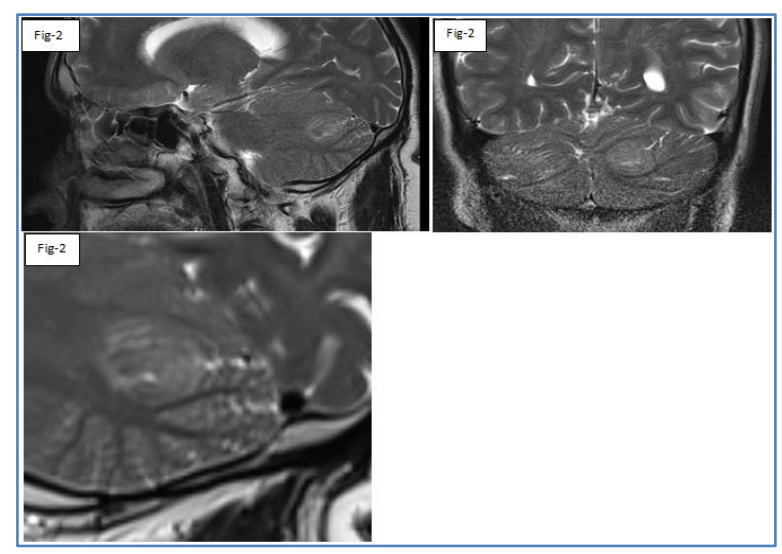

Fig-2: T2-weighted sagittal and coronal MR images shows the mass is predominantly hyperintense, with the typical alternate high- and normal-signalintensity bands

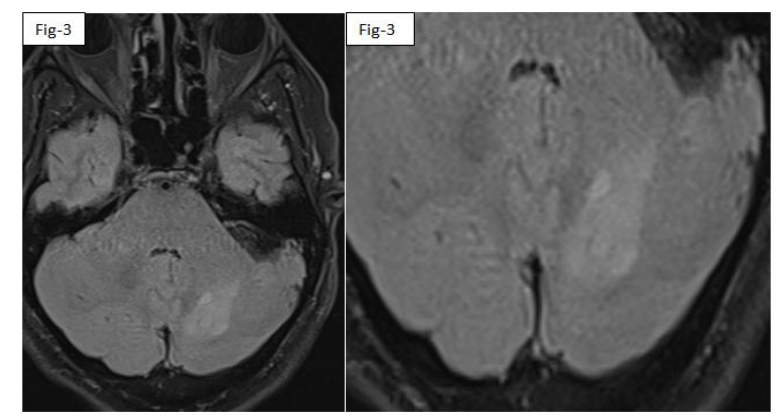

Fig-3: Axial fluid-attenuated inversion-recovery FLAIR MR Image shows the mass is not suppressed

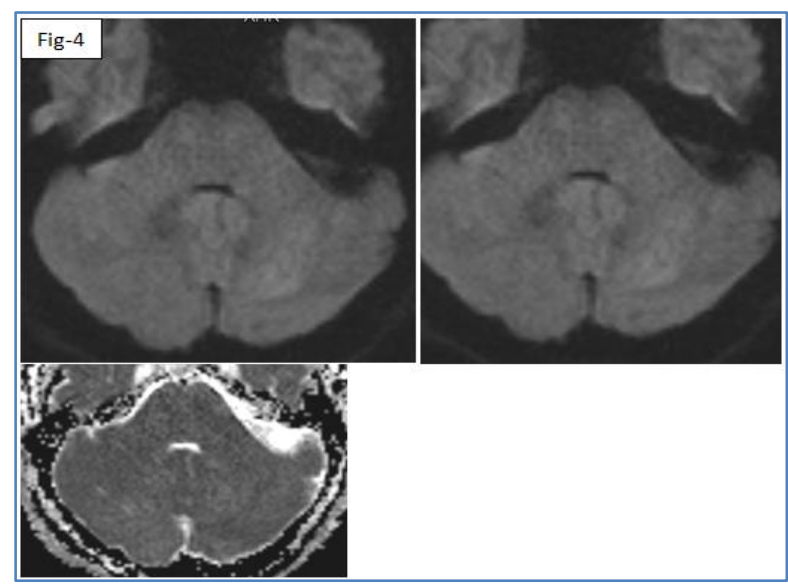

Fig-4: Axial diffusion-weighted (DWI) MR image shows the mass hyperintense, unrestricted diffusion

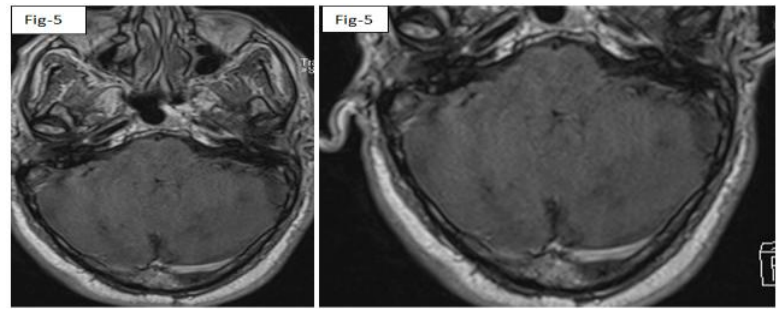

Fig-5: T1-weighted contrast material-enhanced axial MR image: Thin linear enhancement can be seen at the junction of the mass and the adjacent normal cerebellar tissue, but the mass itself does not show any appreciable enhancement

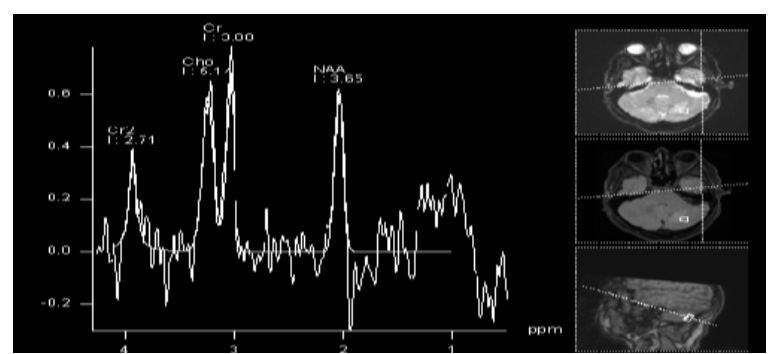

Fig-6: MRSI at DWI: increased Cho and NAA

\section{DiSCUSSION}

Lhermitte-Duclos disease is a rare entity characterized by a hamartomatous lesion in the posterior fossa. Lhermitte-Duclos syndrome is seen most frequently in young adults (average age, 34 years). Less frequently, it occurs in pediatric patients [5]. There is no sex predilection.

Clinically, patients may be asymptomatic, or they may present with symptoms and signs of increased intracranial pressure. Cranial nerve palsies, cerebellar symptoms, and sudden neurologic deterioration because of occlusive hydrocephalus are frequent findings [6]. This disease is commonly associated with other congenital malformations, such as megalencephaly, polydactyly, multiple hemangiomata, and skull abnormalities [7].

Usually, patients have long-standing symptoms that have been present for years, indicating the slowly progressive nature of this disease. Mental retardation may be present [7].

MR imaging plays an important role in the diagnostic process. It is the modality of choice, as it is for any posterior fossa abnormality.

MR imaging reveals a cerebellar mass with a typical striated, corduroy, or tiger-striped folial pattern that consists of alternating bands on both T1- and T2weighted images. The bands are hyper and isointense relative to gray matter on T2-weighted images and isoand hypointense on T1-weighted images [7]. Probably related to the deep running veins between the folia seen on SWI [8]. 
Most cases demonstrate little or no enhancement, although patchy enhancement of the tumor has been described in some series [9]. Calcification is an uncommon finding, but it has been reported [6].

Treatment of choice is surgery offering good clinical results. With some patients, especially those with partial resections, recurrence has been described even after prolonged periods free of disease [10]. In symptomatic patients, it may be necessary to place a ventricular shunt catheter to treat hydrocephalus [10].

The lesion is a low-grade WHO-grade 1 tumour [9]. Histological analysis reveals destruction of the laminar cytoarchitecture of the cerebral cortex with hypertrophy of the molecular layer, as well as dysplastic and hypertrophic neurons in the inner granular layer [11].

Cowden's syndrome, or "neoplasia-hamartoma syndrome", rare and underdiagnosed, is an autosomal dominant genodermatosis with a high incidence of malignant tumors. Several recent clinical cases show that Lhermitte-Duclos disease can be part of Cowden syndrome [12].

Cowden syndrome diagnosis is clinical, based on the association of pathognomonic, major and minor criteria. The association in a patient with thyroid cancer, rarely with multinodular goiter, of typical dermatological manifestations, easily identifiable by clinical examination (papillomatous papules, acral keratoses, trichilemmomas), with a history of breast, endometrial, or renal cancer, or hamartomatous tumors presence, should alert the clinician. Clinical management of patients with Cowden syndrome is multidisciplinary; to include early and frequent screening, surveillance, and preventive care for associated malignancies [4].

\section{Conclusion}

It should be noted that Lhermitte-Duclos and Cowden's disease may be a particular form of phakomatosis. Brain MRI should be performed even without neurological signs due to slow tumor growth. However, these patients should be carefully screened and followed up because of the risk of future cancer.

\section{REFERENCES}

1. Lhermitte, J., Duclos, P. (1920). Sur un ganglioneurome diffus du cortex du cervelet. Bull Assoc Fr Etude Cancer, 9: 99-107.
2. Kulkantrakorn, K., Awwad, E. E., Levy, B., Selhorst, J. B., Cole, H. O., Leake, D., ... \& Malik, M. M. (1997). MRI in Lhermitte-Duclos disease. Neurology, 48(3), 725-731.

3. Marano, S. R., Johnson, P. C., \& Spetzler, R. F. (1988). Recurrent Lhermitte-Duclos disease in a child: case report. Journal of neurosurgery, 69(4), 599-603.

4. Sardinoux, M., Raingeard, I., Bessis, D., Coupier, I., Renard, E., \& Bringer, J. (2010, September). Le syndrome de Cowden ou syndrome des hamartomes multiples en endocrinologie clinique. In Annales d'endocrinologie (Vol. 71, No. 4, pp. 264-273). Elsevier Masson.

5. Roessmann, U., \& Wongmongkolrit, T. (1984). Dysplastic gangliocytoma of cerebellum in a newborn: case report. Journal of neurosurgery, 60(4), 845-847.

6. Milbouw, G., Born, J. D., Martin, D., Collignon, J., Hans, P., Reznik, M., \& Bonnal, J. (1988). Clinical and radiological aspects of dysplastic gangliocytoma (Lhermitte-Duclos disease): a report of two cases with review of the literature. Neurosurgery, 22(1), 124-128.

7. Shinagare, A. B., Patil, N. K., \& Sorte, S. Z. (2009). Case 144: dysplastic cerebellar gangliocytoma (Lhermitte-Duclos disease). Radiology, 251(1), 298-303.

8. Nayil, K., Wani, M., Ramzan, A., Shaheen, F., Lone, I., \& Wani, A. (2011). Lhermitte-Duclos disease with syrinx: case report and literature review. Turkish neurosurgery, 21(4), 651-654.

9. Andres, R. H., Guzman, R., Weis, J., Brekenfeld, C., Fandino, J., \& Seiler, R. W. (2009). LhermitteDuclos disease with atypical vascularization--case report and review of the literature. Clinical neuropathology, 28(2), 83-90.

10. Koeller, K. K., \& Henry, J. M. (2001). From the archives of the AFIP: superficial gliomas: radiologic-pathologic correlation. Radiographics, 21(6), 1533-1556.

11. Perez-Nunez, A., Lagares, A., Benitez, J., Urioste, M., Lobato, R. D., Ricoy, J. R., ... \& Gonzalez, P. (2004). Lhermitte-Duclos disease and Cowden disease: clinical and genetic study in five patients with Lhermitte-Duclos disease and literature review. Acta neurochirurgica, 146(7), 679-690.

12. Peltier, J., Lok, C., Fichten, A., Bruniau, A., Lefranc, M., Toussaint, P., ... \& Le Gars, D. (2006). Lhermitte-duclos disease and Cowden's syndrome: Report of two cases. Neurochirurgie, 52(5), 407-414.

Cite This Article: Baadi F et al (2021). Lhermitte-Duclos Disease is a Component of Cowden Syndrome: Typical MRI Findings. EAS J Radiol Imaging Technol, 3(2), 79-81. 